\title{
RIGOR E LIBERDADE: A CAUSA DE JOÃO GILBERTO
}

\section{Carlos Pires*}

\section{Resumo}

Este estudo é parte introdutória de uma pesquisa em que se pretende caracterizar alguns momentos centrais do trabalho de João Gilberto. Essa caracterização traz elementos para se entender o "projeto utópico" do autor em certo descompasso com a bossa nova e sua cultura de consumo. Este artigo pretende, ainda, mostrar de que maneira a obra de João Gilberto mudou a tradição musical brasileira.

\section{Palavras-chaves}

canção, música popular, João Gilberto, Bossa Nova, cultura brasileira.

\begin{abstract}
This study is part of research which intends to characterize some central moments of João Gilberto's work. This characterization presents João Gilberto's "Utopian Project" in certain disharmony with bossa nova and its consumer culture. This article aims to show in what way João Gilberto's work changed the Brazilian musical tradition.
\end{abstract}

\section{Keywords}

song, popular music, João Gilberto, Bossa Nova, Brazilian culture.

* Doutorando no Programa de Pós-Graduação em Teoria Literária e Literatura Comparada pela na FFLCH-USP. E-mail: pirescarlos@ gmail.com 
oão Gilberto, como é sabido, compôs pouco no sentido de escrever uma letra e uma estrutura musical que corresponda a ela, ou mesmo de criar uma música instrumental - menos de dez músicas suas vieram a público. Partindo de uma composição própria, ou não, o que está em jogo em sua invenção é uma direção formal comum, que imprime aos materiais musicais mobilizados, atualizada em cada apresentação ou novo contexto. Para isso, esses elementos que movimenta precisam preservar certa integridade relacionada à sua situação de origem, o que faz com que as versões de João Gilberto potencializem, nos seus momentos mais felizes, características menos evidentes desse mesmo material. As canções que utiliza em suas "versões" fazem parte de uma experiência da canção e do país que o compositor organiza, hierarquiza, depura, reinventa - em suma, dá direção, ou "tradicionaliza"1 a seu modo. Boa parte da força das suas regravações, tanto de autores clássicos como de quase anônimos, vem de transformar em ato aspectos que as versões anteriores, muitas vezes, apenas insinuavam. Mesmo quando esses aspectos antes se colocavam, o trabalho de João Gilberto potencializa e reapresenta essas características como algo novo - e que, ao mesmo tempo, pode ser melhor percebido na tradição musical do país.

Também é bastante conhecido o fato de João Gilberto ser um ponto de inflexão na música popular nacional, com significativa reverberação para o exterior. Ele transformou, no final da década de 1950, a maneira de tocar violão, de cantar, de - junto com Tom Jobim - harmonizar e arranjar, de conceber o acompanhamento rítmico enfim, praticamente todos os parâmetros musicais da canção foram afetados por seu trabalho. E isso acontece em bloco, como muitas vezes seus acordes, já no primeiro LP, "Chega de saudades", lançado em março de 1959. Sua obra não amadureceu, como é mais comum, dentro da dinâmica de um sistema musical/comercial com pequenos avanços que potencializam uma transformação maior. Isso provavelmente aconteceu, mas as canções que chegaram a público em 1959 já estavam prontas e com raro acabamento. Isso causa a sensação de façanha - que em boa medida foi - que por sua vez provoca certa ofuscação em relação aos contornos efetivos desse fino trabalho. Essa falta de definição se dá, ao que parece, também pelo fato do compositor ser confundido com a bossa nova, movimento que em boa medida faz uso do seu artesanato e das soluções formais de Tom Jobim. Tirando o anedotário e as pesquisas sobre o contexto do movimento e da vida de João Gilberto, importantes para a reflexão sobre esse momento ${ }^{2}$, sobra pouco material sobre o trabalho do músico considerado de maneira praticamente unânime ${ }^{3}$ o de maior importância de um setor decisivo da cultura nacional da segunda metade do século XX.

O termo, como se sabe, é de Mário de Andrade.

A reflexão mais completa nessa direção está no livro de Ruy Castro (CASTRO, 1999).

Até o historiador José Ramos Tinhorão considera João Gilberto uma exceção à crítica que faz à bossa nova, movimento que considera regressivo em relação à tradição nacional do samba (TINHORÃO, 1978, p.226-227). 
Um dos primeiros aspectos que chama atenção nos primeiros discos de João Gilberto é a fatura clara, luminosa, de suas músicas e canções ${ }^{4}$ que acabaram se tornando uma espécie de padrão de medida para muitos músicos. A flutuação da letra e de elementos musicais e uma claridade da canção, não eram, para ele, propriamente um efeito como para muitos de seus seguidores e sim, ao que parece, uma formalização bastante particular, uma espécie de "causa". A construção dessa "causa" envolve na estruturação da canção uma relação moderna, autoconsciente, da voz com o espaço musical - não mais fundo musical - ou, para dizer de outra maneira, João Gilberto busca de forma quase doentia colocar a voz na canção em uma relação de equivalência com a música sem que uma violente a outra, mantendo, ao mesmo tempo, a integridade das duas nesse conflito específico.

Essa maneira de conceber a canção leva a uma reorganização dos outros parâmetros musicais com base nesse princípio formal que em boa medida não admite, nos seus momentos de realização plena, elementos externos ou acessórios. Isso leva a uma construção, que parece encontrar seus limites em uma dimensão ética, em que os dados musicais precisam ser reduzidos a traços fundamentais dentro do funcionamento de músicas que são particulares, que pedem soluções que as individualizem - ou, a cada composição sua, e isso significa a cada apresentação de uma música, esse processo de redução e apresentação da canção nesse espaço musical precisa ser atualizado, posto em xeque, sem que se solidifique em estilo, em uma batida, ou em um jeito de cantar, ou qualquer outra característica a priori que evitaria, ou que se sobressairia, a essa elaboração formal específica.

A construção dessa música "clara", leve, com espaços abertos dentro de complexas estruturas rítmicas, tem, como é comum a qualquer realização humana, uma dimensão prática ${ }^{6}$. Para esse "efeito" - essa "causa" no limite envolve a realização de efeitos - acontecer em uma gravação se fez necessário achar os elementos mínimos constitutivos desse ritmo - esse entendido dentro de uma tradição musical - e reduzi-los a timbres enxutos, com presença física comprimida para que não se espalhem excessivamente no espaço musical e tirem a definição dos outros dados da composição. Essa dinâmica rítmica criada fica, em alguns momentos, por conta exclusiva da voz e do violão cuja presença reduzida no artesanato do autor, como já apontado em outros estudos (MAMMI, 1992; GARCIA, 1999; MELLO, 2001), colabora para a configuração desse espaço vazado, não excessivamente preenchido. Em shows gravados - com a dificuldade maior de delimitar os sons, ou achar uma presença adequada para eles - a redução dos elementos à voz e violão é opção frequente ao longo de sua obra.

4 Como a intenção desta pesquisa - em que este texto, escrito em 2011, funciona, ou pretende funcionar, como uma espécie de introdução - é investigar o trabalho de João Gilberto dentro do contexto de uma tardia arte moderna brasileira, consideramos, como está subentendido anteriormente, suas gravações, ou versões - independente da sua autoria - como suas composições.

5 Clement Greenberg, a quem devo em parte essa formulação, em uma comparação de Picasso com o pintor soviético Repin, diz: “Onde Picasso pinta a causa, Repin pinta o efeito. Repin pré-digere a arte para o espectador e poupa a ele o esforço, proporciona a ele um atalho para o prazer da arte que evita o que é necessariamente difícil na arte genuína" (GREENBERG, 1996. p.33).

6 Luis Tatit chama a atenção para esse fato (TATIT, 1996. p.162-163). 
Um dado curioso é que essa construção rigorosa do espaço musical não conduz a uma geometrização. Ao que parece existe uma espécie de "geometria sem régua", que fica no limite do artesanato - que arredonda os cantos e faz o improvável dar certo. João Gilberto conseguia - e consegue - um tipo de unidade dos materiais que aponta para uma assimilação paradoxal de práticas construtivas, presentes de maneira mais evidente em outros setores da atividade artística da época, diferente da de seus contemporâneos e seguidores - ou, nos termos de Ronaldo Brito, há nele um certo "construtivismo paradoxal" que caracteriza sua produção e de "boa parte da grande arte brasileira moderna" (BRITO, 2005, p.117).

Seu artesanato, como dito, é conduzido em direção a um "efeito" de claridade, limpeza e leveza com o uso "essencial" dos elementos em jogo dentro de uma potente construção rítmica que parece precisar de uma instabilidade de origem, de espaços soltos, que não encontram apoio imediato, e que dão, paradoxalmente, a impressão de que estão em seus lugares. Essa dupla, ou múltipla, temporalidade gerada pela ambiguidade dos apoios dos elementos que constituem esse complexo rítmico é central para a organização dessa forma. Isso parece conferir às músicas uma espécie de ilusão que, para funcionar, depende de certa irregularidade regular ou vice-versa. A sustentação não imediata dos elementos musicais que gera em algumas músicas um calmo não repouso é algo bastante construído. Essa construção “excessiva” poderia conferir certo peso às composições, no entanto provoca a sensação contrária de que essa compacta armação musical flutua, muitas vezes intensificada pelo arranjo.

Até hoje causa certa perplexidade o ensino do "ritmo" bossa nova para bateristas. Nas canções de João Gilberto, a rigor, não existe um padrão do qual seja possível derivar algumas células de variação - nem no violão isso é possível já que isso, segundo o depoimento de Jobim, retira justamente o elemento decisivo do trabalho de João Gilberto, o "cada caso era cada caso" (MELLO, 1976, p.145). O que existe nos "acompanhamentos", principalmente nos primeiros discos, é uma regularidade "reta", que tende a uma repetição "mecânica" - um padrão rigoroso se se quiser - tocado com a mão direita e uma liberdade de acentuação da mão esquerda que testa e põe em dúvida a todo o momento a regularidade da outra mão - fazendo sentido dentro de um arranjo particular, na relação com os outros elementos e não em si mesmo ${ }^{7}$. Isso também foi inventado por João Gilberto com os bateristas que tocaram com ele em um procedimento semelhante ao que usou para "reduzir" os outros elementos da composição. Diminuiu, no "acompanhamento" da bateria, a intensidade e a presença física dos ataques usando em muitos casos a escovinha ou uma condução muito suave na mão direita e o aro da caixa, não mais a pele que provoca uma explosão excessiva, nos "ataques" da mão esquerda. Criou dessa maneira uma equivalência das intensidades em que é possível realizar esse jogo entre regularidade e irregularidade que é central ao seu processo compositivo.

\footnotetext{
O que corresponde em alguma medida à "batida bossa nova" na relação entre "baixo" (polegar) - o elemento mais "fixo" - e o "acorde" (outros dedos) com uma acentuação mais "livre". No trabalho de João Gilberto essa batida também não faz sentido em si, mas dentro de composições, com soluções singulares em "cada caso", para novamente citar Tom Jobim (MELLO, 1976, p.145).
} 
Desse ponto de vista, ou do ponto de vista dessa forma, é possível entender em outra direção a anedota bastante divulgada que conta que João Gilberto dava aos músicos, no lugar de uma partitura descrevendo as mudanças rítmicas ao longo da estrutura musical fixa, um papel com a letra da canção escrita. Para que essa forma tenha desenvolvimento, na maneira como João Gilberto parece dar a entender, é preciso que os parâmetros não estejam pré-fixados ou que a estrutura rítmica não seja construída de fora para dentro por uma partitura no momento em que a atualização da música acontece em uma gravação ou show. O que não significa que não se tenha uma estrutura prévia, ou melhor, uma ideia anterior, poderosa por sinal, que oriente o trabalho. Ao contrário, para que essa ideia se particularize de maneira rigorosa - na verdade para que ela se singularize - é preciso levar em conta parâmetros e disposições subjetivas que nem o rigor dos cartógrafos do famoso conto de Jorge Luis Borges daria conta $^{8}$.

A intensificação do ritmo não se dá nas composições de João Gilberto com o aumento da intensidade - ou da força - do ataque, como o senso comum acreditaria, mas, pelo contrário, com sua redução para encontrar a força certa para que não se violente os elementos mobilizados - que, no entanto, são submetidos a uma unidade musical, são "atritados" até o limite das resistências, em um arranjo bastante exigente. Essa inteligência musical - em que menos é efetivamente mais - causa ruído em um contexto cultural-comercial em que a valorização do produto se dá pelo acréscimo de acessórios em estruturas reconhecíveis ${ }^{9}$, pré-fixadas.

$* * *$

A voz em seus LPs, principalmente nos três primeiros, tem uma presença física maior que outros elementos musicais por se ter acrescentado a ela um volume maior no momento de mixagem - ao mesmo tempo em que a emissão vocal para conferir a ela uma presença mínima, quase imaterial em alguns momentos, aponta em direção diferente, até contrária. Essa voz se comporta no espaço como um elemento musical em equivalência, como dito, aos outros - em alguns trechos as frases do arranjo ou o violão possuem até maior intensidade / volume - em lugares que não atrapalham a clareza dessa emissão vocal. Mas a comparação do padrão da voz em relação ao fundo musical com os discos de época - e até posteriores - revela outra façanha de João Gilberto: sustentar nesse aspecto específico - a relação entre volume da voz e os outros elementos musicais - um conflito com os estúdios brasileiros que para a época deve ter sido monumental ${ }^{10}$. Levando-se em consideração o comportamento dos outros aspectos na

8 Lorenzo Mammi discute essa questão de maneira interessante em seu ensaio: [quando leva um tapete persa em um estúdio pois acha que proporciona uma acústica superior ao carpete etc.] o que João Gilberto defende é a qualidade do som, não mensurável nem funcional (...) São caracteres residuais, incontroláveis; mas para reproduzi-los em um equivalente técnico, o som gravado, é preciso um autocontrole extraordinário." (MAMMI, 1992, p.70).

9 Uma discussão sobre a canção popular e o ritmo de profissionalização da cultura está feita de maneira mais cuidadosa em outro estudo: PIRES, Carlos. "Canção popular e processo social no Tropicalismo", dissertação de mestrado, 2009.

$10 \mathrm{O}$ anedotário em relação ao autor fornece algumas pistas desse conflito: as piadas maldosas em relação a essa voz sem "virilidade", ou o "cantor ventríloquo" etc. Falta ainda material histórico sobre 
composição e sua coerência formal, João Gilberto parece, para dizer o mínimo, não ter saído completamente vitorioso nesse caso - somando-se a isso a conversão desse aborrecimento em consciência, computada até hoje como mania, uma das aparências que um artista rigoroso como ele precisa apresentar no país em situações comerciais para escapar de juízos sociais difusos muitas vezes mais perversos.

A recepção internacional da bossa nova, com exceção de pouquíssimos comentários clarividentes, entende a música de João Gilberto - confundida com a bossa nova - como fundo sobre fundo, como texturas, superfícies suaves, sobre as quais a vida imediata, cotidiana, pode acontecer com mais leveza - isso agravado pelo fato de não se entender o idioma em que a letra é cantada na maioria dos casos, o que retira das canções um momento específico do trabalho, fundamental à criteriosa unidade dos materiais na composição. A tensão específica da canção - a relação entre a voz e o fundo musical, que, como dito, não é bem fundo, pois não está atrás dela - é compreendida e valorizada, nesse contexto internacional, por algo que é quase o seu contrário, por ser uma forma praticamente sem tensão, sem conflito, com elementos voz e música - que funcionam como um grande fundo musical, quase como música ambiente sofisticada, ou, com perdão da expressão de mau gosto, como lounge avant la lettre - o que em alguma medida a bossa nova foi. Essa recepção de João Gilberto no exterior fez com que sua forma de compor seja (re)considerada, também no contexto nacional, tendo como centro uma espécie de homogeneidade na relação entre voz e música que retira do autor a sua característica, talvez, mais importante, essa tensão específica que estabelece nas composições.

"Bim bom" funciona como uma espécie de manifesto" ${ }^{11}$ da música que João Gilberto começa a inventar no final da década de 1950. A construção da canção - a letra mínima, uma estrutura musical que a potencializa não como moldura, nem estabelecendo uma relação ilustrativa com a voz articulada próxima à fala - causou muito do espanto desse cantor "sem voz", ou ventríloquo - segundo a percepção de boa parte do público, de muitos músicos e produtores de discos. Isso associado a uma nova maneira de tocar violão, conceber o ritmo, organizar o arranjo, dividir as frases melódicas, fazia a novidade já procurada por alguns músicos e compositores na década de 1950 - um samba moderno ${ }^{12}$, urbano - e a "estranhice", pouco entendida até hoje, de João Gilberto.

"Chega de saudades" muda - talvez essa seja a transformação mais radical nas artes do país no século XX - os parâmetros, como dito, de realização de um trabalho no

o desenvolvimento técnico do meio musical do final da década de 1950 como o que Zuza de Mello desenvolveu em relação ao momento imediatamente posterior em a "era dos festivais" (MELLO, 2003).

11 Luiz Tatit fala em, junto com Hô-bá-lá-lá, "verdadeiro manifesto do despojamento do conteúdo" (TATIT, 1995, p. 163) e Walter Garcia aposta em seu livro "Bim Bom" na canção como porta de acesso à obra do compositor (GARCIA, 1999).

12 Diversos depoimentos de época e posteriores apontam nessa direção. 
âmbito cultural-comercial. Essa "novidade" em alguma medida estava no horizonte comercial da gravadora: a capa é elaborada com o retrato do jovem João Gilberto, vestido com um urbano e esportivo suéter "Iate Club", olhando em um tom entre o desafio e o enfado - ou "cool" - com uma dramática iluminação em luz e sombra curiosa em um disco em que as músicas acontecem quase como negação ao tom dramático e ao excesso de contraste e clima das composições de época. Esses elementos somados ao título do LP e o nome do autor diagramados de maneira descontínua, mas em bloco, preenchidas com cores pastéis, aludindo a uma suave modernidade, soavam como um desafio que no conjunto ecoa um "basta de bolero ou samba-canção passional ou de cafonice". A provocação comercial tentava ligar o autor à carência de época de uma música nacional feita no "presente" (urbano) que não soasse extravagante ou exagerada em relação, principalmente, à música norte americana que em alguns setores produzia canções menos contrastadas com interpretações e composições mais "frias". Comentando esse ambiente de rápida modernização, Veloso faz um parênteses - um "mas também" - em relação à especificidade de João Gilberto oriunda da sua relação fina com a tradição nacional:

mas também driblando-os [aqueles que tentavam modernizar a música nacional nos fins da década de 1940 e na década de 1950] a todos com uma demonstração de domínio dos procedimentos do cool jazz, então a ponta-de-lança da invenção nos Estados Unidos, dos quais ele fazia um uso que lhe permitiu melhor religar-se ao que sabia ser grande na tradição brasileira: o canto de Orlando Silva e Ciro Monteiro, a composição de Ary Barroso e Dorival Caymmi, de Wilson Batista e Geraldo Pereira, as iluminações de Assis Valente, em suma, todo um mundo de que aqueles modernizadores se queriam desmembrar em seu apego a estilos americanos já meio envelhecidos.

(VELOSO, 1999)

Estava no horizonte de muitos cantores e compositores da época, principalmente nas áreas urbanas de comércio cultural, realizar essa modernização do "ritmo" do país. Mas isso se dava, no entanto, dentro de certa ambiguidade, não sem esquisitas sobreposições, que abrangia desde o "antigo" desejo de se ter no país arte moderna (não sem as ambivalências inerentes a esse aspecto) à chave da cultura industrial americana, como Veloso chama atenção. Essa segunda orientação, que entendia, no limite, a modernização como uma atribuição de uma nova roupagem às velhas formas (nacionais ou não) parece distinta à perspectiva de João Gilberto, pelo que se depreende da seca coerência formal do trabalho, ainda mais se considerada no contexto, e da negação de elementos acessórios na composição. Esse funcionamento cultural particular ampliava sua lógica de funcionamento no país e encontrava eco em alguns estratos sociais, principalmente da classe média, mas não se generalizará, por não se ter as condições materiais para isso, até a segunda metade da década seguinte um dos elementos decisivos na identificação dessa transformação qualitativa desse 
funcionamento cultural, como se sabe, são as empresas responsáveis pelas pesquisas de marketing ${ }^{13}$.

A canção "bim bom" - que foi antes lançada como lado B de um 78 rpm que tinha "Chega de saudades" como a principal - apresentava certas arestas em relação a esse projeto comercial do LP de 1959 que, como dito, buscava um público carente de modernidade, epidérmica ou não. O "meu baião", cantado na música, não trazia de maneira imediata um elemento que se "agregava" para atingir um mercado mais amplo. Pelo contrário, ele traz certo ranço popular e rural, que o público-alvo urbano, pelo que se depreende da concepção do projeto comercial, estava em boa medida querendo afastar do seu ambiente "sofisticado".

O baião foi o primeiro grande fenômeno de massa no país, com certa penetração nas classes médias e altas principalmente pela voz de Carmélia Alves ${ }^{14}$ - de forma orquestrada e como algo pitoresco para os estratos sociais com maior poder aquisitivo e para estrangeiros. No final da década de 1950, no entanto, Luiz Gonzaga idealizador desse ritmo concebido para ser lançado comercialmente ${ }^{15}$ com a canção "baião" em 1946 - estava perdendo seu espaço, que não foi pouco, nos centros urbanos, rádios e dentro da sua gravadora. A mudança do $78 \mathrm{rpm}$ para 33 no fim da década de 1950 marca esse momento que deixa o baião e seu "rei" confinados a uma esfera de circulação popular que funcionava de maneira bastante improvisada, quase circense. Se na época existissem instrumentos de marketing, ou uma "mentalidade cultural" que funcionasse em chave, digamos assim, industrial, ou por meio de pesquisas de marketing, provavelmente não se teria concebido o projeto comercial do LP "Chega de saudades" daquela maneira mantendo em uma de suas principais canções a citação ao gênero musical, o baião, que estava em franca decadência comercial nessa faixa de consumo que o LP pretendia atingir - ainda mais considerando o aspecto imediato de recepção dos conteúdos das letras no país ${ }^{16}$. Se nessa época o meio cultural estivesse funcionando em chave mais "profissional", o LP teria encontrado uma resistência ainda maior do que teve - e parece não ter sido pouca e em diversos níveis (CASTRO, 1999) - e, talvez, tivesse ficado na gaveta (ou nem teria sido gravado).

13 Sobre o assunto, ver Renato Ortis (ORTIS, 1987). É importante diferenciar aqui o "comércio cultural" que se intensifica no país, no campo da música popular, a partir dos nos anos 30 e um sistema, digamos assim, mais integrado, na direção em que Adorno e Horkheimer descreveram, de funcionamento cultural. No país é possível identificar algo aproximado a isso com as particularidades locais, segundo os estudos de Renato Ortis, na segunda metade da década de 1960. Em estudo anterior já citado tentamos investigar como as canções tropicalistas apresentavam em seus centros formais os dilemas desse momento de "profissionalização" da cultura nacional.

14 Quando foi coroada "Rainha do Baião" por Luiz Gonzaga em seu programa de rádio "No mundo do baião", Carmélia Alves comenta sobre a coroa (um chapéu de couro do nordeste) que recebe e o ambiente em que tocava: "Claro que não ia usar essa indumentária, porque trabalhando na boate do Copacabana [palace], eu cantava baião soirée. O meu baião era com orquestra. Luiz [Gonzaga], ele, sempre nas origens, me dizia: 'Você vai com a elite na society, e eu vou com o povão, pé no chão'", (DREYFUS, 1996).

15 O "baião" é uma estilização feita por Luiz Gonzaga do "respiro" presente nos cantos de desafio, ou, nos termos do folclorista Luís de Câmara Cascudo, era "um pequeno trecho musical executado pelas violas nos intervalos do canto no desafio".

16 Muito se falou no momento em que João Gilberto foi lançado no "cantor desafinado" por conta da canção "desafinado" e da "estranhice" da sua voz para a época. Na "boca miúda" ele era conhecido como "aquele cantor desafinado" 
O baião, no entanto, já apresentava uma década antes, na voz e sanfona de Luiz Gonzaga, um contraponto à hegemonia do samba-canção e do bolero. Segundo o crítico musical José Ramos Tinhorão:

(...)[o baião] o novo tipo de canção popular e ritmo de dança explodiu em 1946 no mercado musical saturado de boleros e sambas-canções abolerados como uma redescoberta da vitalidade rítmica.

(TINHORÃO, 1978)

João Gilberto estava operando sua tradicionalização da experiência musical do país em uma direção particular, atento às diversas dicções, ritmos e com independência em relação ao "bom gosto" ou "sofisticação de fachada" onipresentes no comércio cultural "fino" do país.

De qualquer maneira, o "baião" de "bim bom" - "é só isso meu baião" - não é tão evidente como boa parte da crítica dá a entender - e é menos evidente ainda o aproveitamento que João Gilberto faz dele na composição. A ênfase, em muitos baiões "atoadados" de Luiz Gonzaga, de praticamente todas as sílabas na linha melódica - ou, nos termos de Luiz Tatit, "os impulsos (...) conduzidos pelas vogais sem a participação direta de ataques ou de aliterações das consoantes" (TATIT, 1996, p. 153), faz, nesse sentido, de "bim bom" uma espécie de "baião átono" em que as sílabas, com a centralidade também das vogais, são apenas circunscritas com precisão pela emissão vocal mínima - o que sugere continuidade no verso, por esse caráter regular e átono da emissão, ao mesmo tempo em que as sílabas são precisas, bem delimitadas ${ }^{17}$.

A organização do verso e seu comportamento melódico se assemelham a importantes e conhecidas composições de Luiz Gonzaga, causando um efeito estético, no entanto, diverso a essa filiação enunciada. O baião, na verdade baião-toada, fica cifrado, obscuro na percepção imediata do ouvinte que deixa se levar quase inteiramente pelo ritmo particular da canção, lugar que seria mais evidente, ou mais imediato, procurar essa forma citada (entendendo-a como "gênero musical", quase um sinônimo de "ritmo", padrão rítmico, em sua acepção no comércio cultural).

Pode-se descrever desta maneira o trecho da canção abaixo:

\author{
É só isso meu baião \\ e não tem mais nada não \\ o meu coração / pediu assim... só
}

17 Lorenzo Mammi, no estudo mais completo e consistente feito sobre João Gilberto, investigando a genealogia de seu canto aponta para os elementos aprendidos com Mário Reis - "a precisão milimétrica [na emissão das sílabas]” (p. 67) - e para a diferença em relação a ele, que é a procura da continuidade nos versos, e não da segmentação. Algo não muito distinto, acreditamos, do que estamos tentando dizer, em outra origem - o baião de Luiz Gonzaga - que pode ser complementar à perspectiva de Mammi: como o cantor e compositor deu conta dos aspectos da prosódia da língua "brasileira" que ao mesmo tempo "resiste às marcações rígidas, tentando arredondá-las. Isso unido à tendência em certa medida contrária (e complementar) a reforçar os acentos (sobretudo onde há uma seqüência de monossílabos), cria já na prosódia um movimento sincopado” (Mammi, 1992, p. 66). 
Duas redondilhas, acentuadas na terceira e última sílaba (em Gonzaga eventualmente na quinta, como em "e não tem mais nada não"), em que as vogais predominam quase sem o atrito ou o ruído consonantal - com a emissão que individualiza cada sílaba (de maneira "átona", que dá em boa medida o caráter de continuidade) - finalizada por um verso com dois momentos de cinco sílabas cada (que podem ser considerados dois versos) com o comportamento similar, uma acentuação na quinta ou na quarta e/ou quinta sílabas. Essa caracterização do comportamento dos versos em "Bim bom" serviria, dobrando-se o último verso, para descrever os baiõestoada "Asa branca" ou "Assum preto" de Luiz Gonzaga:

\section{Inté mesmo a asa branca \\ bateu asas do sertão \\ entonce eu disse / adeus rosinha \\ guarda contigo / meu coração}

O comportamento melódico parece, em certa medida, também derivado dessas canções de Luiz Gonzaga. Nos dois versos iniciais da estrofe há a ascensão para a região mais aguda da tessitura até a terceira sílaba em "bim bom" - e a continuação dessa ascensão até a quarta sílaba em uma tessitura ampliada em Gonzaga - e o declínio com o último acento do verso ascendendo um tom em "bim bom" - e o comportamento variável repetindo esse padrão ou terminando o desenho descendente nesses baiões. Os dois versos finais das estrofes de Gonzaga têm estruturas melódicas que variam praticamente a cada construção - e variam esses desenhos, também, quando os mesmos versos são repetidos - enquanto "bim bom" só tem um padrão para o único verso, “o meu coração pediu assim".

Essas semelhanças, como dito, não são de percepção imediata já que "Bim bom" apresenta uma fatura muito diferente do baião-toada de Luiz Gonzaga. Mas uma alegre melancolia, ou uma melancólica alegria, para insistir um pouco mais no argumento, parece, também, ter como origem o baião-toada - por meio dessas características descritas anteriormente que o compositor baiano soube aproveitar em outra direção - juntando, como Gonzaga, os elementos que em boa medida estavam em espaços sociais distintos: a música para dançar, para o corpo, em que o carnaval é o melhor exemplo, e a "lírica amorosa", do samba-canção ou boleros das rádios, com seus temas de perda amorosa, sofrimento subjetivo ${ }^{18}$ etc, das canções de meio de ano - uma música, exagerando, "para a cabeça". Essa possibilidade compositiva gera um efeito de sentido caro à bossa nova que rapidamente se solidifica em estilo, ou moda, em certa tristeza/alegria "cool" - o que curiosamente parece dar característica urbana, "civilizada", ao movimento - que João Gilberto soube desentranhar, com sua cuidadosa atenção à tradição musical do país, de um lugar social que não condiz com a fachada de sofisticação do movimento, ou com a modernização epidérmica que orienta a produção comercial do seu primeiro LP. A "causa” de João Gilberto parece ter um horizonte mais amplo e generoso.

18 Uma boa análise - que ajudou a fundamentar nosso argumento - de como essas questões aparecem em duas canções de Gonzaga foi realizada por Luis Tatit (TATIT, 1996, p.148-159). 


\section{Referências bibliográficas}

BRITO, Ronaldo. Experiência crítica. São Paulo: Cosac \& Naify, 2005.

CASTRO, Ruy. Chega de Saudade: a história e as histórias da Bossa Nova. São Paulo:Companhia das Letras, 1999.

DREYFUS, Dominique. A saga de Luiz Gonzaga. São Paulo: Ed. 34, 1996.

GARCIA, W. Bim Bom: a contradição sem conflitos de João Gilberto. São Paulo: Paz e terra, 1999.

GREENBERG, C. Arte e cultura. São Paulo: Editora ática, 1996.

MAMMI, L. "João Gilberto e o projeto utópico da Bossa Nova". Novos Estudos CEBRAP, $\mathrm{n}^{\circ} 34$, novembro, 1992. São Paulo: CEBRAP.

MELLO, José Eduardo Homem de. Música Popular Brasileira. São Paulo: melhoramentos / Edusp, 1976.

MELLO, Zuza Homem de. A era dos festivais. São Paulo: Ed. 34, 2003. . João Gilberto. São Paulo: Publifolha, 2001.

ORTIZ, Renato. A Moderna Tradição Brasileira. São Paulo: Brasiliense, 1987.

TATIT, L. O século da canção. Cotia: Ateliê editorial, 2004. . O cancionista - Composição de canções no Brasil. São Paulo: Edusp, 1995. . Análise semiótica através das letras. Cotia: Atelier editorial, 2002.

TINHORÃO, José Ramos. Pequena história da música popular. São Paulo: Círculo do Livro, 1978.

VELOSO, Caetano. Verdade Tropical. São Paulo: Companhia das Letras, 1999. 